\title{
Genotype by Environment Interaction Effects on Nutraceutical Lipid Compounds of Pigmented Rice (Oryza sativa L. ssp. indica)
}

\author{
Bhornchai Harakotr ${ }^{(D},{ }^{1}$ Kasidid Prompoh, ${ }^{1}$ Khundej Suriharn $\mathbb{D D}^{2}$ and Kamol Lertrat ${ }^{3}$ \\ ${ }^{1}$ Department of Agricultural Technology, Faculty of Science and Technology, Thammasat University, Pathum Thani 12120, \\ Thailand \\ ${ }^{2}$ Department of Agronomy, Faculty of Agriculture, Khon Kaen University, Khon Kaen 40002, Thailand \\ ${ }^{3}$ Plant Breeding Research Center for Sustainable Agriculture, Faculty of Agriculture, Khon Kaen University, \\ Khon Kaen 40002, Thailand
}

Correspondence should be addressed to Bhornchai Harakotr; harakotr@tu.ac.th

Received 1 October 2020; Revised 26 January 2021; Accepted 2 February 2021; Published 22 February 2021

Academic Editor: Maria Serrano

Copyright (c) 2021 Bhornchai Harakotr et al. This is an open access article distributed under the Creative Commons Attribution License, which permits unrestricted use, distribution, and reproduction in any medium, provided the original work is properly cited.

\begin{abstract}
To identify a rice genotype with a wider or specific adaptability, the magnitude and patterns of genotype interaction with the environment are valuable clues. However, such information on the nutraceutical lipid compound in rice is limited. In this study, concentrations of five pigmented rice genotypes with different lipid compound levels were evaluated for $\alpha$-tocopherol, $\gamma$-oryzanol, phytosterols, octacosanol, and squalene contents. The research was conducted in eight environments (four locations and two years). Combined analysis of variance showed that levels of $\alpha$-tocopherol, $\gamma$-oryzanol, octacosanol, and squalene were mainly affected by genotype, accounting for more than $42.57 \%$ of the total variance. This suggests that improvement of these traits may be achieved by using conventional rice breeding methods. A large proportion of the variation in campesterol and $\beta$-sitosterol contents was contributed by the environment. The effect of genotype by environment was significant for all observed traits, especially for $\gamma$-oryzanol, $\beta$-sitosterol, and squalene. This complicates identification of superior genotypes for these compounds across all environments. Stability parameters showed rice genotypes with high levels of nutraceutical lipid compounds to be sensitive to changes in environmental conditions; thus, specific adaptation is suitable. Our findings suggest that rice breeders and producers should be testing and selecting rice genotypes possessing high added-value lipid concentrations in specific growing conditions or regions.
\end{abstract}

\section{Introduction}

Rice (Oryza sativa L.) is consumed as a carbohydrate and energy source by over one-half of the world's population. Over $90 \%$ of rice production is in Asia [1]. The grains contain more than a hundred bioactive compounds, including phytic acid, isovitexin, flavonoids, phenolics, polyphenols, anthocyanins, and proanthocyanins. Previously unknown compounds have been identified, characterized, and quantified in rice [2]. Rice also contains a high level of nutraceutical lipid compounds, such as vitamin E (refers to any of the 8 naturally occurring forms, $\alpha, \beta, \gamma$, and $\delta$ species of both tocotrienols and tocopherols), $\gamma$-oryzanol (ferulic acid ester of phytosterols), phytosterols, octacosanol, and squalene [3-6]. These usually are associated as potent antioxidants and have provided various health benefits, for instance, to inhibit cholesterol oxidation, to reduce serum cholesterol levels in animals, and to deter tumor growth [7-9]. Yield of rice is the primary interest to farmers all over the world; therefore, nonpigmented rice is superior to pigmented rice in yield and its components $[6,10]$. However, pigmented rice cultivars, with red, purple, black, brown, and yellow kernels, are still grown in some areas in Asia because of either their nutritional and medicinal values or as part of traditional cultural practices [11]. Previous studies reported that pigmented rice has higher nutritive values of micronutrients and important bioactive compounds than nonpigmented rice $[10,12]$. Moreover, this specialty rice is used 
as a natural food coloring and aromatic in the local markets, due to its unique fragrance [13].

An important goal of crop breeding is to improve the productivity or yields [14]. The development of higher yielding varieties with enhanced nutraceutical lipid content through conventional breeding methods is economically positive for growers while widening consumer choices [15]. Knowledge to heritability of yield and nutraceutical compounds accelerates genetic gains. However, these are complex traits of which expression depends on genotype, environment, and the interaction between them [15-19]. The study of such interactions has been extensive focusing on $\alpha$-tocopherol and $\gamma$-oryzanol. No report on phytosterols, octacosanol, or squalene is available. Understanding the relationship between nutraceutical lipid contents and growing conditions allows rice breeders and growers to target their rice genotypes for adaptation to specific growing environments or regions.

Three models have commonly been applied to assess the adaptability and stability of tested genotypes across environments in some crop species, namely, (1) Eberhart-Russell [20], (2) additive main effects and multiplicative interaction (AMMI) [1, 21, 22], and (3) mixed models [14, 23]. The use of regression techniques has been improved by Eberhart-Russell [20] and is widely used to estimate the genotype by environment interactions on grain yield and yield components of rice [24-26]. An understanding of the effect of such interaction on the phenotypic stability of nutraceutical lipid compounds allows breeders and producers to select optimal genotypes for both general and specific adaptation. The objective of this study was to evaluate the effect of genotype by environment interactions on $\alpha$-tocopherol, $\gamma$-oryzanol, phytosterols, octacosanol, and squalene contents of pigmented rice.

\section{Materials and Methods}

2.1. Plant Materials, Experimental Site, and Experimental Design. Five pigmented rice genotypes were selected based on grain morphology and nutraceutical lipid compounds [27]. The newly improved TU-001 rice genotype is popular and broadly cultivated in Thailand, whereas other four genotypes (TU-055, TU-153, TU-211, and TU-234) are traditional Thai rice landraces (Table 1). These genotypes were assigned in a randomized complete block design (RCBD) with three replications and were evaluated at four locations (Pathum Thani, Sakon Nakhon, Ubon Ratchathani, and Roi-Et) over two consecutive years (growing seasons 2017 and 2018). The Pathum Thani location was selected because it is the hub of rice production in the central plain of Thailand. Roi-Et is an important area for aromatic rice cultivation. Other two locations were selected as they are on farm conservative landrace rice fields in the northeast of Thailand. Seedlings were transplanted at a hill spacing of $25 \times 25 \mathrm{~cm}$ with a seedling per hill. Soil preparation, planting, and other agronomic practices were controlled uniformly following the recommendations of Good Agricultural Practices (GAP) for Thai rice [28]. Ten panicles per genotype were randomly harvested at the correct harvest time $(80-85 \%$ of the grains are straw with $20-25 \%$ of moisture content) of the GAP index and then oven-dried at $50^{\circ} \mathrm{C}$ to achieve a moisture content below $14 \%$. Seeds were manually dehulled prior to milling. Samples were milled to be a fine powder (mod. CM190, Cemotec ${ }^{\mathrm{TM}}$, Denmark), passed through a 100 -mesh screen, thoroughly mixed, and stored at $-20^{\circ} \mathrm{C}$ until analysis.

2.2. Soil Properties. The experimental fields at each location were changed in each year, but these were adjacent. Pathum Thani is located at $+14.07450,+0.6094167$, and $7.3 \mathrm{~m}$ above the sea level. This site had acidic clay soil $(\mathrm{pH}=4.82$ to 4.91$)$, poor total nitrogen (0.08\%), available phosphorus (3.85 ppm), and high extractable potassium (165.96 ppm). Sakon Nakhon $(+17.34656,+104.1157)$ had sandy loam soil, and it is located at $176.2 \mathrm{~m}$ above the sea level. The organic matter $(1.60 \%)$, total nitrogen $(0.08 \%)$, available phosphorus $(8.20 \mathrm{ppm})$, and extractable potassium $(94.90 \mathrm{ppm})$ were moderate. Ubon Ratchathani is located at +14.61883 , +105.1729 , and $159.0 \mathrm{~m}$ above the sea level. The soil texture was sandy with $1.20 \%$ organic matter, $0.06 \%$ total nitrogen, $8.43 \mathrm{ppm}$ available phosphorus, and $51.01 \mathrm{ppm}$ extractable potassium. Roi-Et is located at $+16.07106,+103.6031$, and $160.8 \mathrm{~m}$ above the sea level. The soil texture was saline sandy loam with high cation exchange capacity (21.85 e.mol. $\left.\mathrm{kg}^{-1}\right)$, but low organic matter $(0.95 \%)$, total nitrogen $(0.05 \%)$, available phosphorus $(5.20 \mathrm{ppm})$, and extractable potassium (35.00 ppm).

2.3. Weather Data. Weather data including total rainfall, relative humidity, temperature, and solar radiation were collected from the nearest meteorological stations. Weather data for eight growing environments are listed in Table 2 and Figure 1S. The average daily temperatures during the rice growing season ranged from $22.2^{\circ} \mathrm{C}$ to $33.8^{\circ} \mathrm{C}$, and solar radiation during the grain filling stage ranged from 13.04 to $17.49 \mathrm{MJ} \mathrm{m}^{-2}$ day $^{-1}$. Relative humidity ranged from $52.1 \%$ to $95.3 \%$, and total rainfall throughout the rice growing season ranged from 567 to $1,060 \mathrm{~mm}$. The Pathum Thani site in the 2017 and 2018 rice growing seasons had the highest average temperature but the lowest solar radiation during the grain filling stage. The Roi-Et site had the lowest temperature and average relative humidity in both rice growing seasons, but the solar radiation was the highest. Total rainfall at Sakon Nakhon in the 2018 growing season was the highest at $1,060 \mathrm{~mm}$, but in 2017, it was the lowest at $567 \mathrm{~mm}$. The Pathum Thani site had the highest average rainfall across two growing seasons.

2.4. $\alpha$-Tocopherol and $\gamma$-Oryzanol Determinations. Simultaneous determination of $\alpha$-tocopherol and $\gamma$-oryzanol was conducted following Butsat and Siriamornpun [29] with slight modifications. One gram of powdered rice sample was extracted using $10 \mathrm{~mL}$ acetone and vortexed at maximum speed for $1 \mathrm{~min}$. The solutions were centrifuged at $2500 \mathrm{rpm}$ for $20 \mathrm{~min}$, after which the solvent was removed. The upper layer was combined before evaporating to dryness in a low 
TABLE 1: Rice genotypes used in this study.

\begin{tabular}{|c|c|c|c|c|c|}
\hline \multirow{2}{*}{ Genotype } & \multirow{2}{*}{ Pedigree } & \multirow{2}{*}{ Type } & \multicolumn{2}{|c|}{ Brown rice grain } & \multirow{2}{*}{ Lipid compound levels } \\
\hline & & & Shape & Color & \\
\hline TU-001 & Tubtim-Chumpae & NG & Slender & Red & High level of all lipid compounds excluding octacosanol \\
\hline TU-055 & Kum-Noii & NG & Medium & Black & Low level of all lipid compounds \\
\hline TU-153 & Kum-Pluek-Kao & G & Slender & Purple & Moderate level of most lipid compounds but high octacosanol \\
\hline TU-211 & Ma-Li-Daeng & NG & Medium & Red & Moderate level of most lipid compounds but low $\alpha$-tocopherol and campesterol \\
\hline TU-234 & $\begin{array}{c}\text { Khao-Neaw- } \\
\text { Daeng }\end{array}$ & G & Slender & Red & Moderate level of most lipid compounds but low $\beta$-sitosterol and squalene \\
\hline
\end{tabular}

G, glutinous rice; NG, nonglutinous rice.

TAвle 2: Meteorological conditions in Pathum Thani, Sakon Nakhon, Ubon Ratchathani, and Roi-Et provinces in the 2017 and 2018 growing seasons.

\begin{tabular}{|c|c|c|c|c|c|c|c|}
\hline \multirow[t]{2}{*}{ Environment } & \multirow[t]{2}{*}{ Transplanting date } & \multicolumn{2}{|c|}{$\begin{array}{c}\text { Temperature } \\
\left({ }^{\circ} \mathrm{C}\right)\end{array}$} & \multicolumn{2}{|c|}{$\begin{array}{c}\text { Relative } \\
\text { humidity (\%) }\end{array}$} & \multirow[t]{2}{*}{ Rainfall (mm) } & \multirow{2}{*}{$\begin{array}{l}\text { Solar radiation } \\
\left(\mathrm{MJ} . \mathrm{m}^{-2} \text { day }^{-1}\right)\end{array}$} \\
\hline & & Min & $\operatorname{Max}$ & Min & Max & & \\
\hline $\begin{array}{l}\text { Pathum Thani (PT17) } \\
\text { (PT) }\end{array}$ & June 2017 & 24.9 & 33.1 & 53.7 & 93.4 & 993 & 13.19 \\
\hline Sakon Nakhon (SK17) & May 2017 & 23.1 & 31.8 & 57.8 & 93.3 & 567 & 17.00 \\
\hline Ubon Ratchathani (UB17) & May 2017 & 22.4 & 31.2 & 59.0 & 94.9 & 670 & 17.17 \\
\hline Roi-Et (RE17) & June 2017 & 22.2 & 31.0 & 52.1 & 90.1 & 592 & 17.49 \\
\hline Pathum Thani (PT18) & June 2018 & 25.7 & 33.8 & 57.5 & 92.8 & 918 & 13.04 \\
\hline Sakon Nakhon (SK18) & May 2018 & 23.8 & 31.4 & 58.5 & 93.2 & 1,060 & 16.80 \\
\hline Ubon Ratchathani (UB18) & May 2018 & 23.4 & 31.9 & 59.3 & 95.3 & 924 & 17.07 \\
\hline Roi-Et (RE18) & June 2018 & 23.1 & 32.2 & 53.7 & 90.4 & 886 & 17.15 \\
\hline
\end{tabular}

temperature vacuum evaporator. The residual was further extracted twice, and determinations were made in triplicate.

Reversed-phase HPLC analysis was performed using a Shimadzu system (mod. LC-20AC, Shimadzu Corporation, Japan) equipped with a binary pump (LC-20AC pump) and a diode array detector (SPD-M20A). Chromatographic separation was performed on an XSelect CHS C-18 column $(4.6 \times 250 \mathrm{~mm}$, i.d., $5 \mu \mathrm{m})$ (Waters Corporation, USA). The mobile phase consisted of acetonitrile/methanol $(25: 75 \mathrm{v} / \mathrm{v})$ at a flow rate of $1.5 \mathrm{ml} / \mathrm{min}$. The solution was passed through a $0.22 \mu \mathrm{m}$ filter (Merck Millipore Corporation, USA). Operating conditions were as follows: column temperature $38^{\circ} \mathrm{C}$, injection volume $20 \mu \mathrm{l}$, and photodiode-array detector at $292 \mathrm{~nm}$ for $\alpha$-tocopherol and $325 \mathrm{~nm} \gamma$-oryzanol. Dilutions of individual external standards from low to high concentrations were made, and standard curves were plotted. The lipid contents were expressed as $\mu \mathrm{g}$ per $\mathrm{g}$ of dry weight.

\subsection{Phytosterols, Octacosanol, and Squalene Determinations.} Simultaneous chromatographic separation of phytosterols, octacosanol, and squalene was conducted with GC-MS following Siriamornpun et al. [30] with slight modifications. Two major fractions of phytosterols $[3,27]$, namely, campesterol and $\beta$-sitosterol were emphasized in this study. One gram of powdered brown rice was placed to a screw-capped tube containing $1 \mathrm{mg}$ of 5 - $\alpha$-cholestane as internal standard and $5 \mathrm{ml}$ of synthetic antioxidant (ethanolic pyrogallol). The solutions were saponified with $2 \mathrm{ml}$ of $\mathrm{KOH}(600 \mathrm{ppm})$ and $2 \mathrm{ml}$ of ethanol, $\mathrm{NaCl}(10 \mathrm{ppm})$. The tubes were placed in a waterbath and heated at $70^{\circ} \mathrm{C}$, then mixed every $10 \mathrm{~min}$ for a
$45 \mathrm{~min}$ digestion period. The solutions were cooled in an ice bath for $10 \mathrm{~min}$; then, $10 \mathrm{ml}$ of $\mathrm{NaCl}(10 \mathrm{ppm})$ was added. The suspension was extracted twice using $10 \mathrm{ml}$ of $n$-hexane/ ethyl acetate $(9: 1 \mathrm{v} / \mathrm{v})$. The upper organic layer was collected and dried in a low temperature vacuum evaporator. The dry residue was derivatized with $100 \mu \mathrm{l}$ of BSTFA : TMCS (99:1 $\mathrm{v} / \mathrm{v})$ and $1 \mathrm{ml}$ of pyridine $(99 \%)$ at $60^{\circ} \mathrm{C}$ for $30 \mathrm{~min}$. The residue was dissolved in $2 \mathrm{ml}$ of hexane, and the resulting clear solution $(1 \mu \mathrm{l})$ was injected into a GC-MS system (mod. QP2010, Shimadzu Corporation, Japan) equipped with a HP5 column ( $30 \mathrm{~m}, 0.25 \mathrm{~mm}$ i.d., $0.25 \mu \mathrm{m}$ film thickness). The injector temperature was held at $280^{\circ} \mathrm{C}$ throughout analysis and the transfer line temperature at $230^{\circ} \mathrm{C}$. Separation was performed on a fused-silica capillary column Rtx5Ms (5\% diphenyl 95\% dimethyl polysiloxane, $30 \mathrm{~m}$ length, $0.25 \mathrm{~mm}$ i.d., $0.25 \mu \mathrm{m}$ film thickness; Restek, Bellefonte, PA, USA) and Rtx-5 (5\% diphenyl 95\% dimethyl polysiloxane, $30 \mathrm{~m}$ length, $0.25 \mathrm{~mm}$ i.d., $0.25 \mu \mathrm{m}$ film thickness; Restek, USA), using helium as carrier gas. The initial column temperature of $60^{\circ} \mathrm{C}$ was held for $1 \mathrm{~min}$, increased at $30^{\circ} \mathrm{C}$ $\min ^{-1}$ to $250^{\circ} \mathrm{C}$ and held for $10 \mathrm{~min}$, raised to $280^{\circ} \mathrm{C}$ at a rate of $1^{\circ} \mathrm{C} \mathrm{min}{ }^{-1}$, and maintained at this temperature for further $13 \mathrm{~min}$. The lipid compounds were identified by comparing their mass spectra and retention times with those internal standards.

2.6. Statistical Analysis. All observed traits were statistically analyzed for each environment. Error variances were tested for homogeneity using Barlett's test as described by Gomez and Gomez [31]. Means of genotypes and environments were compared by least significant difference (LSD) at 
$\alpha<0.05$ using STATISTIX software (version 10.0, Analytical Software, Tallahassee, IL, USA). Combined ANOVA was performed using the following statistical model:

$$
Y_{i j}=m+E_{i}+G_{j}+G E_{i j}+e_{i j}
$$

where $Y_{i j}$ is the observed value of genotype $j$ at environment $i, m$ is the grand mean value across environments, $E_{i}$ is the environmental effect, $G_{j}$ is the genotype effect, $G E_{i j}$ is the interaction effect of genotype by environment, and $e_{i j}$ is the pooled error.

Once significant interactions between genotype and environment had been noticed, stability parameters were calculated following Eberhart and Russell [20]. Means across environments, linear regression coefficients $(b)$, and deviation from regressions $\left(\mathrm{Sd}^{2}\right)$ of genotype means over environmental index were calculated. The regression coefficient $(b)$ was first tested for difference from 0 and, if significant, tested for differences from 1.

\section{Results}

Combined analysis of variance for nutraceutical lipid compounds is presented in Table 3. Genotype, environment, and genotype by environment interaction were significant for all nutraceutical lipid compounds. Genotype was predominant for $\alpha$-tocopherol, $\gamma$-oryzanol, octacosanol, and squalene contents $(50.08,48.70,47.24$, and $42.57 \%$ of total variation, respectively). Campesterol and $\beta$-sitosterol levels showed high variation due to environment, accounting for $43.37 \%$ and $37.38 \%$ of total variation, respectively. However, the genotype effect on these two compounds was small, accounting for $28.38 \%$ and $28.06 \%$ of total variation, respectively. Genotype and genotype by environment interaction were equally important on squalene content, accounting for $42.57 \%$ and $40.01 \%$ of total variation, respectively. Genotype by environment interaction contributed $15.90 \%$ to the total variance on $\alpha$-tocopherol content. This result suggested that our tested genotypes performed consistently across locations.

As the effect of genotype by environment interaction existed, the means of five pigmented rice genotypes for nutraceutical lipid contents in each environment were used to rank the environmental effects on each compound [32]. Table 4 presents comprehensive genotype by environment analysis. Among tested rice genotypes, TU-001 consistently showed the highest content of $\alpha$-tocopherol, $\gamma$-oryzanol, campesterol, $\beta$-sitosterol, and squalene across all environments. The highest octacosanol value was found in TU-234 rice genotype. However, these two genotypes performed poorly in unfavourable environments. TU-055, which had the lowest values for all lipid compounds in our preliminary study [29], showed consistently the lowest values for $\gamma$-oryzanol, $\beta$-sitosterol, and squalene across locations. The lowest $\alpha$-tocopherol and campesterol contents were found in TU-211. These two genotypes showed the highest levels of lipid compounds when growing in unfavourable environments, but otherwise performed poorly. TU-211 did poorly on campesterol content in all environments except in Ubon
Ratchathani in both growing seasons (31.84 and $11.37 \%$ higher than the grand mean, respectively). The results demonstrated that expression of all observed lipid compounds is strongly influenced by both genetic and environmental factors. To maximize production of these compounds, the genotypes must be selected according to their suitable environment. The pigmented rice genotypes harvested in Sakon Nakhon in both growing seasons exhibited the highest $\gamma$-oryzanol and octacosanol contents. The highest campesterol, $\beta$-sitosterol, and squalene contents were obtained from Pathum Thani in both growing seasons. Samples harvested from Roi-Et had the lowest $\alpha$-tocopherol, campesterol, and octacosanol contents. The lowest $\gamma$-oryzanol and $\beta$-sitosterol contents were obtained from Pathum Thani and Ubon Ratchathani, respectively. These results suggested that differences in lipid contents reflected the growing locations and some climatic conditions, which did not differ between the growing seasons.

Stability analysis of five pigmented rice genotypes on nutraceutical lipid compounds is shown in Table 5. Eberhart and Russell [20] noted that a stable genotype should produce a high mean value and unit regression coefficient and the smallest deviation from regression. A genotype with a regression coefficient higher than one is considered unstable and highly sensitive to environmental change; thus, it is directed to specific adaptation. A regression coefficient below one suggests that the genotype is relatively stable with greater tolerance for environmental changes. TU-001 had the highest $\alpha$-tocopherol content (871 $\mu \mathrm{g} / \mathrm{g}$ of dry weight) followed by TU-055, but these genotypes had higher regression coefficients $\left(b=1.50^{*}\right.$ and $1.38^{*}$, respectively). This result indicated the promising performance of TU-001 and TU-055 in favourable environments. TU-234 showed good stability for $\alpha$-tocopherol content with a regression coefficient of $b=0.95^{\mathrm{ns}}$. However, its lipid content was lower than the location means, meaning that it was stable in diverse environments with a low lipid content. TU-001 had the highest $\gamma$-oryzanol content $(19,660 \mu \mathrm{g} / \mathrm{g}$ of dry weight). Its regression coefficient of $b=-0.43^{* *}$ for this compound was not significantly different from 0 . High stability for $\gamma$-oryzanol content was observed in TU-055 and TU-153 $\left(b=0.79^{\text {ns }}\right.$ and $0.64^{\text {ns }}$, respectively). However, TU-153 had a higher $\gamma$-oryzanol content than TU-055. All genotypes had high stability $\left(b=0.81^{\mathrm{ns}}-1.05^{\mathrm{ns}}\right)$ for campesterol content. TU-001 contained the highest level of this lipid with a location mean of $914 \mu \mathrm{g} / \mathrm{g}$ of dry weight and had high both regression coefficient $\left(b=1.24^{*}\right)$ and deviation from regression (292.69). As a result, this genotype was highly sensitive to the environmental changes. TU-001 had the highest $\beta$-sitosterol and squalene contents with high regression coefficients of $2.02^{* *}$ and $2.59^{* *}$, respectively. This rice genotype is, however, very sensitive to changes in contrasting growing conditions and had to be proposed for specific adaptation. TU-153 that had the highest octacosanol content $(1,646 \mu \mathrm{g} /$ g of dry weight) with high regression coefficient $\left(b=2.85^{* *}\right)$ indicated that this genotype performed well only under favourable environmental conditions. Smaller regression coefficients were observed for TU-055, TU-153, and TU- 
TABLE 3: Combined analysis of variance for nutraceutical lipid contents of five pigmented rice genotypes evaluated across eight environments, 2017-2018.

\begin{tabular}{|c|c|c|c|c|c|c|c|}
\hline \multirow{2}{*}{ Source } & \multirow{2}{*}{$\mathrm{d} f$} & \multicolumn{6}{|c|}{ Nutraceutical lipid compounds } \\
\hline & & $\alpha$-Tocopherol & $\gamma$-Oryzanol & Campesterol & $\beta$-Sitosterol & Octacosanol & Squalene \\
\hline Environment (E) & 7 & $\begin{array}{c}402,761 \\
(33.82)^{* *}\end{array}$ & $\begin{array}{l}1.20 \times 10^{8} \\
(19.59)^{* *}\end{array}$ & $\begin{array}{c}603,940 \\
(43.37)^{* *}\end{array}$ & $\begin{array}{l}1.01 \times 10^{8} \\
(37.38)^{* *}\end{array}$ & $\begin{array}{l}1,141,719 \\
(22.72)^{* *}\end{array}$ & $\begin{array}{c}968 \\
(16.85)^{* *}\end{array}$ \\
\hline Error $(\mathrm{E} \times \operatorname{Rep})^{\mathrm{a}}$ & 8 & $\begin{array}{c}551 \\
(0.05)\end{array}$ & $\begin{array}{c}285,430 \\
(0.05)\end{array}$ & $\begin{array}{c}729 \\
(0.06)\end{array}$ & $\begin{array}{l}8,076 \\
(0.01)\end{array}$ & $\begin{array}{c}459 \\
(0.01)\end{array}$ & $\begin{array}{c}4.41 \\
(0.09)\end{array}$ \\
\hline Genotype (G) & 4 & $\begin{array}{c}249,151 \\
(50.08)^{* *}\end{array}$ & $\begin{array}{l}5.20 \times 10^{8} \\
(48.70)^{* *}\end{array}$ & $\begin{array}{c}691,715 \\
(28.38)^{* *}\end{array}$ & $\begin{array}{l}1.33 \times 10^{8} \\
(28.06)^{* *}\end{array}$ & $\begin{array}{l}4,155,000 \\
(47.24)^{* *}\end{array}$ & $\begin{array}{c}4,070 \\
(42.57)^{* *}\end{array}$ \\
\hline $\mathrm{G} \times \mathrm{E}$ & 28 & $\begin{array}{c}160,859 \\
(15.90)^{* *}\end{array}$ & $\begin{array}{l}4.80 \times 10^{7} \\
(31.48)^{* *}\end{array}$ & $\begin{array}{c}97,311 \\
(27.95)^{* *}\end{array}$ & $\begin{array}{l}2.34 \times 10^{7} \\
(34.52)^{* *}\end{array}$ & $\begin{array}{c}376,785 \\
(29.99)^{* *}\end{array}$ & $\begin{array}{c}605 \\
(40.01)^{* *}\end{array}$ \\
\hline Error $(G \times \operatorname{Rep} \times E)^{b}$ & 32 & $\begin{array}{c}368 \\
(0.14)\end{array}$ & $\begin{array}{c}254,672 \\
(0.19)\end{array}$ & $\begin{array}{c}712 \\
(0.23)\end{array}$ & $\begin{array}{l}16,036 \\
(0.03)\end{array}$ & $\begin{array}{c}431 \\
(0.04)\end{array}$ & $\begin{array}{c}6.11 \\
(0.49)\end{array}$ \\
\hline C.V. $(\%)^{\mathrm{a}}$ & & 7.71 & 4.75 & 4.35 & 2.04 & 4.25 & 1.82 \\
\hline C.V. $(\%)^{\mathrm{b}}$ & & 7.52 & 4.19 & 5.40 & 2.86 & 4.06 & 3.00 \\
\hline
\end{tabular}

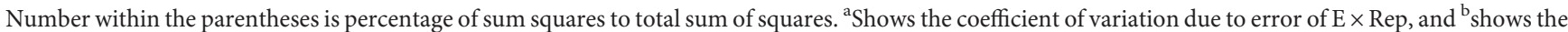
coefficient of variation due to error of $\mathrm{G} \times \operatorname{Rep} \times \mathrm{E}$. ${ }^{* *}$ Significant at $P \leq 0.01$ probability level.

TABLE 4: Nutraceutical lipid compounds of five pigmented rice genotypes evaluated across eight environments during $2017-2018$.

\begin{tabular}{|c|c|c|c|c|c|c|c|c|c|}
\hline \multirow{2}{*}{ Genotypes } & \multicolumn{8}{|c|}{ Environments } & \multirow{2}{*}{ Mean } \\
\hline & PT17 & SK17 & UB17 & RE17 & PT18 & SK18 & UB18 & RE18 & \\
\hline \multicolumn{10}{|c|}{$\alpha$-Tocopherol content } \\
\hline TU-001 & $1,062^{\mathrm{al} /}$ & $1,294^{\mathrm{a}}$ & $821^{\mathrm{b}}$ & $429^{\mathrm{a}}$ & $894^{\mathrm{a}}$ & $943^{\mathrm{a}}$ & $1,209^{\mathrm{a}}$ & $316^{\mathrm{a}}$ & $871^{\mathrm{A} 2 /}$ \\
\hline TU-055 & $625^{\mathrm{b}}$ & $574^{\mathrm{b}}$ & $895^{\mathrm{a}}$ & $294^{\mathrm{b}}$ & $544^{\mathrm{b}}$ & $431^{\mathrm{b}}$ & $1,134^{\mathrm{b}}$ & $240^{\mathrm{b}}$ & $592^{\mathrm{B}}$ \\
\hline TU-153 & $237^{\mathrm{d}}$ & $356^{\mathrm{c}}$ & $513^{c}$ & $120^{\mathrm{d}}$ & $188^{\mathrm{c}}$ & $174^{\mathrm{d}}$ & $447^{\mathrm{d}}$ & $164^{\mathrm{c}}$ & $275^{\mathrm{D}}$ \\
\hline TU-211 & $145^{\mathrm{e}}$ & $313^{\mathrm{c}}$ & $346^{\mathrm{d}}$ & $113^{\mathrm{d}}$ & $123^{\mathrm{c}}$ & $483^{\mathrm{b}}$ & $434^{\mathrm{d}}$ & $105^{\mathrm{d}}$ & $258^{\mathrm{E}}$ \\
\hline TU-234 & $346^{\mathrm{c}}$ & $532^{\mathrm{b}}$ & $530^{\mathrm{c}}$ & $158^{\mathrm{c}}$ & $519^{\mathrm{b}}$ & $315^{\mathrm{c}}$ & $752^{\mathrm{c}}$ & $179^{c}$ & $416^{\mathrm{C}}$ \\
\hline Mean & $483^{\mathrm{C}}$ & $614^{\mathrm{B}}$ & $621^{\mathrm{B}}$ & $233^{\mathrm{E}}$ & $454^{\mathrm{D}}$ & $469^{\mathrm{CD}}$ & $795^{\mathrm{A}}$ & $201^{\mathrm{E}}$ & \\
\hline$F$-test & $* *$ & $* *$ & $* *$ & $* *$ & $* *$ & $* *$ & $* *$ & $* *$ & \\
\hline C.V. (\%) & 4.05 & 2.59 & 2.07 & 1.18 & 6.24 & 6.87 & 1.26 & 6.68 & \\
\hline \multicolumn{10}{|c|}{$\gamma$-Oryzanol content } \\
\hline TU-001 & $7,680^{\mathrm{a}}$ & $15,536^{\mathrm{bc}}$ & $18,210^{\mathrm{a}}$ & $23,224^{\mathrm{a}}$ & $20,385^{\mathrm{a}}$ & $13,880^{\mathrm{c}}$ & $23,950^{\mathrm{a}}$ & $24,414^{\mathrm{a}}$ & $19,660^{\mathrm{A}}$ \\
\hline TU-055 & $1,507^{\mathrm{d}}$ & $7,224^{\mathrm{d}}$ & $6,885^{\mathrm{e}}$ & $4,880^{\mathrm{e}}$ & $1,047^{\mathrm{d}}$ & $8,695^{\mathrm{d}}$ & $8,902^{\mathrm{d}}$ & $6,508^{c}$ & $5,706^{\mathrm{E}}$ \\
\hline TU-153 & $10,332^{\mathrm{b}}$ & $15,722^{\mathrm{b}}$ & $14,706^{\mathrm{c}}$ & $8,069^{c}$ & $13,721^{\mathrm{b}}$ & $16,674^{\mathrm{b}}$ & $14,061^{\mathrm{b}}$ & $7,440^{c}$ & $12,561^{\mathrm{C}}$ \\
\hline TU-211 & $1,658^{\mathrm{d}}$ & $14,166^{\mathrm{c}}$ & $10,382^{\mathrm{d}}$ & $6,035^{\mathrm{d}}$ & $1,410^{\mathrm{d}}$ & $13,231^{\mathrm{c}}$ & $11,219^{c}$ & $6,846^{\mathrm{c}}$ & $8,116^{\mathrm{D}}$ \\
\hline TU-234 & $6,080^{c}$ & $31,439^{a}$ & $15,369^{\mathrm{b}}$ & $10,503^{b}$ & $6,952^{c}$ & $30,290^{\mathrm{a}}$ & $14,471^{\mathrm{b}}$ & $14,090^{\mathrm{b}}$ & $16,149^{\mathrm{B}}$ \\
\hline Mean & $7,452^{\mathrm{G}}$ & $16,817^{\mathrm{A}}$ & $13,110^{\mathrm{C}}$ & $10,542^{\mathrm{E}}$ & $8,703^{\mathrm{F}}$ & $16,550^{\mathrm{A}}$ & $14,521^{\mathrm{B}}$ & $11,859^{\mathrm{D}}$ & \\
\hline$F$-test & $* *$ & $* *$ & $* *$ & $* *$ & $* *$ & $* *$ & $* *$ & $* *$ & \\
\hline C.V. (\%) & 3.78 & 3.32 & 2.60 & 3.81 & 2.50 & 4.75 & 1.10 & 7.51 & \\
\hline \multicolumn{10}{|c|}{ Campesterol content } \\
\hline TU-001 & $1,473^{\mathrm{a}}$ & $1,720^{\mathrm{a}}$ & $824^{\mathrm{b}}$ & $928^{\mathrm{a}}$ & $1,705^{\mathrm{a}}$ & $1,661^{\mathrm{a}}$ & $905^{\mathrm{b}}$ & $912^{\mathrm{a}}$ & $1,264^{\mathrm{A}}$ \\
\hline TU-055 & $1,094^{\mathrm{c}}$ & $1,067^{\mathrm{b}}$ & $680^{c}$ & $390^{c}$ & $990^{\mathrm{d}}$ & $666^{\mathrm{c}}$ & $983^{\mathrm{a}}$ & $537^{\mathrm{c}}$ & $801^{\mathrm{C}}$ \\
\hline TU-153 & $1,052^{\mathrm{c}}$ & $962^{c}$ & $680^{c}$ & $502^{\mathrm{b}}$ & $1,162^{\mathrm{c}}$ & $849^{\mathrm{b}}$ & $501^{\mathrm{c}}$ & $611^{\mathrm{b}}$ & $790^{\mathrm{C}}$ \\
\hline TU-211 & $942^{\mathrm{d}}$ & $847^{\mathrm{d}}$ & $1,205^{\mathrm{a}}$ & $339^{c}$ & $889^{\mathrm{d}}$ & $561^{\mathrm{c}}$ & $1,018^{\mathrm{a}}$ & $341^{\mathrm{d}}$ & $768^{\mathrm{D}}$ \\
\hline TU-234 & $1,363^{\mathrm{b}}$ & $951^{\mathrm{c}}$ & $844^{\mathrm{b}}$ & $559^{\mathrm{b}}$ & $1,403^{\mathrm{b}}$ & $606^{\mathrm{c}}$ & $998^{\mathrm{a}}$ & $868^{\mathrm{a}}$ & $948^{\mathrm{B}}$ \\
\hline Mean & $1,185^{\mathrm{B}}$ & $1,106^{\mathrm{C}}$ & $847^{\mathrm{E}}$ & $544^{\mathrm{G}}$ & $1,230^{\mathrm{A}}$ & $869^{\mathrm{DE}}$ & $879^{\mathrm{D}}$ & $654^{\mathrm{F}}$ & \\
\hline$F$-test & $* *$ & $* *$ & $* *$ & $* *$ & $* *$ & $* *$ & $* *$ & $* *$ & \\
\hline C.V. (\%) & 2.48 & 2.26 & 1.40 & 4.26 & 3.31 & 4.50 & 1.62 & 2.56 & \\
\hline \multirow[t]{2}{*}{ Genotypes } & Environments & Mean & & & & & & & \\
\hline & PT17 & SK17 & UB17 & RE17 & PT18 & SK18 & UB18 & RE18 & \\
\hline \multicolumn{10}{|c|}{$\beta$-Sitosterol content } \\
\hline TU-001 & $19,165^{a}$ & $10,244^{\mathrm{a}}$ & $1,226^{\mathrm{c}}$ & $5,352^{\mathrm{a}}$ & $14,896^{\mathrm{a}}$ & $11,244^{\mathrm{a}}$ & $1,299^{c}$ & $3,002^{\mathrm{a}}$ & $8,303^{\mathrm{A}}$ \\
\hline TU-055 & $1,137^{\mathrm{d}}$ & $2,956^{\mathrm{c}}$ & $762^{\mathrm{d}}$ & $845^{\mathrm{e}}$ & $1,315^{\mathrm{e}}$ & $877^{\mathrm{e}}$ & $866^{\mathrm{d}}$ & $477^{\mathrm{c}}$ & $1,154^{\mathrm{D}}$ \\
\hline TU-153 & $6,883^{\mathrm{c}}$ & $1,431^{\mathrm{d}}$ & $7,161^{\mathrm{a}}$ & $1,191^{\mathrm{d}}$ & $5,248^{\mathrm{d}}$ & $1,507^{\mathrm{d}}$ & $5,426^{\mathrm{a}}$ & $1,862^{\mathrm{b}}$ & $3,838^{\mathrm{C}}$ \\
\hline TU-211 & $17,565^{\mathrm{b}}$ & $9,410^{\mathrm{b}}$ & $571^{\mathrm{e}}$ & $3,055^{\mathrm{b}}$ & $12,776^{\mathrm{b}}$ & $8,964^{\mathrm{b}}$ & $525^{\mathrm{e}}$ & $2,810^{\mathrm{a}}$ & $6,959^{\mathrm{B}}$ \\
\hline TU-234 & $7,339^{c}$ & $777^{\mathrm{e}}$ & $1,446^{\mathrm{b}}$ & $2,055^{\mathrm{c}}$ & $7,863^{\mathrm{c}}$ & $2,192^{\mathrm{c}}$ & $1,923^{\mathrm{b}}$ & $2,827^{\mathrm{a}}$ & $3,303^{C}$ \\
\hline Mean & $10,418^{\mathrm{A}}$ & $4,946^{\mathrm{C}}$ & $2,234^{\mathrm{F}}$ & $2,500^{\mathrm{D}}$ & $8,420^{\mathrm{B}}$ & $4,957^{\mathrm{C}}$ & $2,008^{\mathrm{F}}$ & $2,196^{\mathrm{E}}$ & \\
\hline$F$-test & $* *$ & $* *$ & $* *$ & $* *$ & $* *$ & $* *$ & $* *$ & $* *$ & \\
\hline
\end{tabular}


TABle 4: Continued.

\begin{tabular}{|c|c|c|c|c|c|c|c|c|c|}
\hline \multirow{2}{*}{ Genotypes } & \multicolumn{8}{|c|}{ Environments } & \multirow{2}{*}{ Mean } \\
\hline & PT17 & SK17 & UB17 & RE17 & PT18 & SK18 & UB18 & RE18 & \\
\hline C.V. (\%) & 2.75 & 2.24 & 1.26 & 1.62 & 1.08 & 1.67 & 2.65 & 5.28 & \\
\hline \multicolumn{10}{|c|}{ Octacosanol content } \\
\hline TU-001 & $338^{d}$ & $347^{\mathrm{e}}$ & $256^{\mathrm{d}}$ & $221^{\mathrm{d}}$ & $328^{\mathrm{e}}$ & $407^{\mathrm{d}}$ & $325^{\mathrm{d}}$ & $283^{\mathrm{d}}$ & $313^{\mathrm{E}}$ \\
\hline TU-055 & $587^{\mathrm{C}}$ & $662^{\mathrm{d}}$ & $232^{\mathrm{d}}$ & $236^{\mathrm{d}}$ & $511^{\mathrm{d}}$ & $684^{\mathrm{c}}$ & $360^{\mathrm{d}}$ & $790^{\mathrm{a}}$ & $508^{\mathrm{D}}$ \\
\hline TU-153 & $2,051^{\mathrm{a}}$ & $3,467^{\mathrm{a}}$ & $858^{\mathrm{c}}$ & $820^{\mathrm{a}}$ & $1,489^{\mathrm{a}}$ & $2,418^{\mathrm{a}}$ & $1,735^{\mathrm{a}}$ & $332^{c}$ & $1,646^{\mathrm{A}}$ \\
\hline TU-211 & $695^{\mathrm{b}}$ & $966^{c}$ & $983^{\mathrm{b}}$ & $423^{c}$ & $581^{c}$ & $1,417^{\mathrm{b}}$ & $1,064^{\mathrm{b}}$ & $375^{\mathrm{b}}$ & $813^{\mathrm{C}}$ \\
\hline TU-234 & $726^{\mathrm{b}}$ & $1,274^{\mathrm{b}}$ & $1,036^{\mathrm{a}}$ & $575^{\mathrm{b}}$ & $761^{\mathrm{b}}$ & $1,414^{\mathrm{b}}$ & $772^{\mathrm{c}}$ & $325^{\mathrm{c}}$ & $860^{\mathrm{B}}$ \\
\hline Mean & $880^{\mathrm{C}}$ & $1,343^{\mathrm{A}}$ & $673^{\mathrm{F}}$ & $455^{\mathrm{G}}$ & $734 \mathrm{E}$ & $1,268^{\mathrm{B}}$ & $851^{\mathrm{D}}$ & $421^{\mathrm{H}}$ & \\
\hline$F$-test & $* *$ & $* *$ & $* *$ & $* *$ & $* *$ & $* *$ & $* *$ & $* *$ & \\
\hline C.V. (\%) & 2.05 & 1.59 & 2.50 & 2.55 & 1.87 & 3.31 & 2.47 & 1.53 & \\
\hline \multicolumn{10}{|c|}{ Squalene content } \\
\hline TU-001 & $280^{\mathrm{a}}$ & $194^{\mathrm{a}}$ & $188^{\mathrm{a}}$ & $188^{\mathrm{a}}$ & $201^{\mathrm{a}}$ & $190^{\mathrm{a}}$ & $182^{\mathrm{a}}$ & $186^{\mathrm{a}}$ & $201^{\mathrm{A}}$ \\
\hline TU-055 & $164^{\mathrm{c}}$ & $102^{\mathrm{d}}$ & $164^{\mathrm{b}}$ & $167^{\mathrm{c}}$ & $167^{\mathrm{e}}$ & $166^{\mathrm{e}}$ & $166^{\mathrm{d}}$ & $165^{\mathrm{e}}$ & $158^{\mathrm{E}}$ \\
\hline TU-153 & $188^{\mathrm{b}}$ & $187^{\mathrm{a}}$ & $186^{\mathrm{a}}$ & $177^{\mathrm{b}}$ & $183^{\mathrm{b}}$ & $187^{\mathrm{b}}$ & $178^{\mathrm{b}}$ & $178^{\mathrm{b}}$ & $183^{\mathrm{B}}$ \\
\hline TU-211 & $182^{\mathrm{b}}$ & $169^{\mathrm{b}}$ & $174^{\mathrm{b}}$ & $170^{\mathrm{c}}$ & $179^{c}$ & $177^{\mathrm{c}}$ & $178^{\mathrm{b}}$ & $176^{\mathrm{c}}$ & $176^{\mathrm{C}}$ \\
\hline TU-234 & $168^{\mathrm{c}}$ & $153^{\mathrm{c}}$ & $173^{\mathrm{b}}$ & $169^{c}$ & $177^{\mathrm{d}}$ & $173^{\mathrm{d}}$ & $168^{\mathrm{c}}$ & $167^{\mathrm{d}}$ & $169^{\mathrm{D}}$ \\
\hline Mean & $197^{\mathrm{A}}$ & $161^{\mathrm{E}}$ & $177^{\mathrm{C}}$ & $174^{\mathrm{D}}$ & $182^{\mathrm{B}}$ & $179^{\mathrm{C}}$ & $175^{\mathrm{D}}$ & $174^{\mathrm{D}}$ & \\
\hline$F$-test & $* *$ & $* *$ & $* *$ & $* *$ & $* *$ & $* *$ & $* *$ & $* *$ & \\
\hline C.V. (\%) & 1.25 & 3.01 & 2.21 & 0.91 & 0.33 & 0.42 & 0.33 & 0.25 & \\
\hline
\end{tabular}

PT17, Pathum Thani location in the growing season 2017; SK17, Sakon Nakhon location in the growing season 2017; UB17. Ubon Ratchathani location in the growing season 2017; RE17, Roi-Et location in the growing season 2017; PT18, Pathum Thani location in the growing season 2018; SK18, Sakon Nakhon location in the growing season 2018; UB18, Ubon Ratchathani location in the growing season 2018; RE18, Roi-Et location in the growing season 2018. ${ }^{* *}$ Significant at $P \leq 0.01$ probability level. ${ }^{1 /}$ Means in the same column followed by a common letter are significantly different at $P \leq 0.05$ by LSD.

${ }^{2 /}$ Different capital letter indicates significant difference between environments and between genotypes at $P \leq 0.05$ by LSD.

211, making them more suitable for unfavourable growth conditions.

\section{Discussion}

The grain appearance and nutritional quality traits of rice are determined by multiple genes that make the performance of a genotype dependent on environmental conditions [33]. The present study is the first to evaluate variation in lipid compound content of different pigmented rice genotypes at four locations over two growing seasons. Our previous study had investigated various rice genotypes based on comparisons of rice grown in a single year [27]. It was not possible to estimate the magnitude of genotype by environment interaction effects, which was necessary to determine the reproductivity of ranking based on genotype and/or environment. In this present study, variations due to environment were large for $\alpha$-tocopherol, campesterol, and $\beta$-sitosterol, accounting for $33.82-43.37 \%$ of total variances. This suggests that rice breeders who are carrying out their breeding programs on nutraceutical lipid contents have to evaluate their candidates of rice genotypes in multiple environments. A similar finding was noted by Belleggia et al. [34] who found that phytosterol levels in durum wheat were contributed by environmental factors.

At the same time, it was apparent that the genotype factor played a significant role on $\alpha$-tocopherol, $\gamma$-oryzanol, octacosanol, and squalene contents. Genotype factor is highly significant when compared to other sources of variation, accounting for $42.57-50.08 \%$ of total variance. The effect of interaction between genotype and environment accounted for little of total variance in these lipid contents. The results suggested that all observed lipid contents, excluding squalene content, were heritable, and the phenotypic selection for these parameters would be possible. Previous studies reported that the genotype factor had a greater influence on oil and fatty acid contents than the seasonal factor [17]. In contrary, Bergman and $\mathrm{Xu}$ [16] concluded that the growing environment was more predominant than genotype on $\mathrm{E}$ vitamers and $\gamma$-oryzanol levels. Other related studies reported that $\gamma$-oryzanol content in rice grain was affected by genotype, environment, and grain morphology [29, 35]. Therefore, this study confirmed that the contents of observed nutraceutical lipid compounds were influenced not only by the genetic background but also by the environments and their interaction.

Among four experimental sites, Pathum Thani produced the greatest campesterol, $\beta$-sitosterol, and squalene contents. This location had the highest average temperature but lower solar radiation at the grain filling stage. These weather profiles might encourage the rapid accumulation of phytosterols and squalene contents. This assumption was corroborated by Kuczyńska et al. [36] who found that the greatest content of sterols in barley was observed at high temperature. Expression of the LTP2 gene may be indirectly involved in the abiotic stress reaction by mediating intracellular transport of some lipid classes. Squalene and phytosterol contents are linked, as phytosterol is synthesized from squalene via squalene-2,3-epoxide [4, 18]. Pathum Thani had lower solar radiation at the rice grain filling stage (13.04-13.19 $\mathrm{MJ} \mathrm{m}^{-2} \mathrm{day}^{-1}$ ) than other locations (16.80-17.49 $\left.\mathrm{MJ} \mathrm{m}^{-2} \mathrm{day}^{-1}\right)$. However, the role of light 


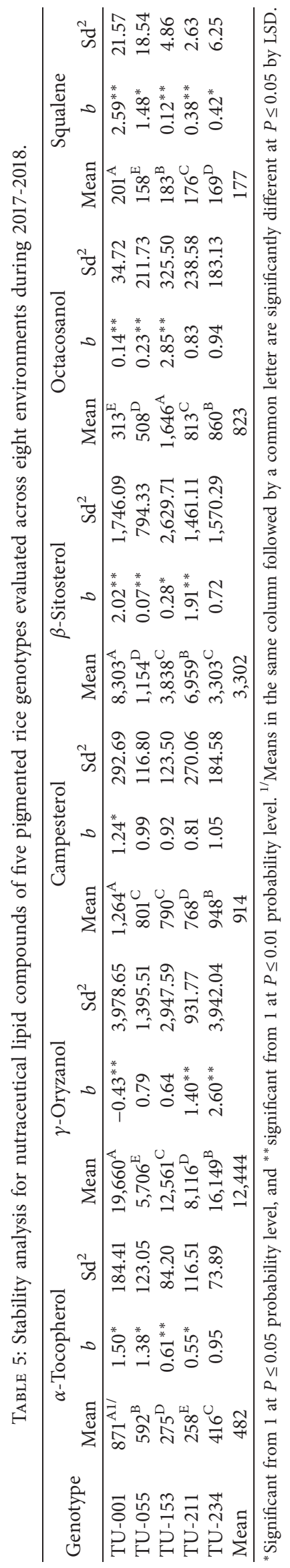


intensity and light stress on phytosterol and squalene contents during rice grain development remains poorly understood. Aguirreza'bal et al. [37] reported that a reduction in intercepted solar radiation during the grain filling stage decreased the oil concentration of sunflower. In addition, Pathum Thani had typical clay soil with low $\mathrm{pH}$ and $\mathrm{P}$ bioavailability. The effect of $\mathrm{P}$ deficiency on lipid contents of rice is still unclear. It should be noted that these abiotic stresses acted to enhance lipid contents.

Environmental factors, especially during the grain filling stage, can significantly affect grain quality characteristics [38]. The highest $\gamma$-oryzanol and octacosanol contents were obtained at Sakon Nakhon, which had the lowest temperature during the grain filling stage (35 days after anthesis) across both growing seasons (Figure 1S). The greatest $\alpha$-tocopherol level was obtained from Ubon Ratchathani, which had a low temperature during the grain filling stage. Similar results were reported by Marwede et al. [39]. Wang et al. [40] reported that tocopherols are essential for cold stress tolerance in rice. A map-based cloning strategy and subsequent complementation test showed that SGD1 encodes homogentisate phytyltransferase (HPT), a key enzyme in tocopherol biosynthesis. The lowest $\alpha$-tocopherol content was obtained from Roi-Et location, where it possessed the lowest rainfall level at the postanthesis period. Thus, the result confirmed the previous report of Belleggia et al. [34] who noted that rainfall was a critical parameter of environmental factors in tocopherol accumulation. Our results suggested that the contents of $\gamma$-oryzanol, octacosanol, and $\alpha$-tocopherol correlated with environmental factors during the grain filling stage.

Soil salt damage is an abiotic stress that may alter physiological and biochemical functions of plants and reduce crop yields of many species [23, 41]. In general, $\alpha$-tocopherol, campesterol, and octacosanol contents were lower in Roi-Et than those in Sakon Nakhon and Ubon Ratchathani. Roi-Et had a sandy soil with high C.E.C. that may reduce lipid contents. Butsat and Siriamornpun [29] reported that soil salinity affected $\alpha$-tocopherol content in KDML 105 rice grown at three different sites in Roi-Et. Under high salinity, $\alpha$-tocopherol concentration of rice grains decreased significantly while grain $\gamma$-oryzanol and tocotrienols increased [41]. However, our current study cannot clearly indicate which important environmental parameters were responsible for the variation of nutraceutical lipid compounds. Further studies are encouraged to investigate individual enzymes regulating these compounds of rice and their overall pathways resulting in the differential lipid compositions and levels during stress or extreme environment.

The significant effect of genotype by environment interaction on nutraceutical lipid concentrations indicated that at least one tested genotype performed differently in different environments. This suggested that specific pigmented rice genotypes should be selected for distinct environment. Although only five rice genotypes were examined in this study, a strong effect of genotype by environment interaction on the contents of all nutraceutical lipid compounds were revealed. Rice genotype
TU-234 performed consistently for $\alpha$-tocopherol, campesterol, $\beta$-sitosterol, and octacosanol across eight environments, as indicated by moderate levels of all lipid compounds, regression values almost equal to one, and low deviation according to the Eberhart and Russell [20] model. This genotype was the most stable among our five tested genotypes; however, its medium levels of lipid compounds was unprofitable for large commercial scale. Instead, it could still be utilized by farmers having either low-input technologies or marginal areas. The newly developed rice genotype TU-001 had the best yield of nutraceutical lipid compounds with the highest $\alpha$-tocopherol, $\gamma$-oryzanol, campesterol, $\beta$-sitosterol, and squalene contents. While, rice landrace genotype TU-153 had the greatest octacosanol content. However, both TU001 and TU-153 had high linear regression $b$ and standard deviation, indicating that these genotypes are very sensitive to environmental conditions and must be grown in favourable environment. The pigmented rice genotypes with high levels of nutraceutical lipids were highly sensitive to the growing conditions, while those with medium or low lipid contents showed less sensitivity. In comparison to modern rice cultivars, rice landraces had more complex genetic backgrounds and more abundant genetic diversity and heterogeneity. They showed strong adaptability to the environment and excellent grain quality [42]. The improved rice genotype TU-001 was predominant on nutraceutical lipid compounds, except on octacosanol, when compared to other landrace rice genotypes. This rice genotype has recently been released in Thailand. It was developed from parental lines with high bioactive contents. The goal was to improve its performance under unfavourable conditions. The results from this study suggest that the genetic background, rather than the genetic origin (modern or landrace), is the major source of variation for nutraceutical lipid contents. Dissection of gene variation related to nutraceutical lipid compound biosynthesis in rice can support the improvement of strains through breeding activities. This may yield benefits for human health [13]. Moreover, further studies are required to elucidate the mechanisms of nutraceutical lipid compound biosynthesis in rice by using omics technologies coupled with bioinformatics.

\section{Conclusions}

Rice genotype TU-234 was the only one suitable for wider adaptation in terms of $\alpha$-tocopherol, campesterol, $\beta$-sitosterol, and octacosanol contents. Genotype TU-001 was a good source of $\alpha$-tocopherol, $\gamma$-oryzanol, campesterol, $\beta$-sitosterol, and squalene contents, whereas genotype TU153 was promising for octacosanol content. However, these rice genotypes were very sensitive to any environmental changes, showed specific adaptation, and could perform well in favourable environments. This study suggests that variation on nutraceutical lipid contents in pigmented rice genotypes can be exploited by selecting genotypes that are suited to specific environments. 


\section{Data Availability}

All data analyzed to support the findings of this research are included in this research article.

\section{Disclosure}

The funding sponsor had no role in the design of the study; in the data collection, analyses, or interpretation; in the writing of the manuscript; and in the decision to publish the results.

\section{Conflicts of Interest}

The authors declare that there are no conflicts of interest.

\section{Acknowledgments}

This study was supported by the Research Grant for New Scholar, Thailand Research Fund (Grant no. MRG5980124). An acknowledgement is extended to the Department of Agricultural Technology, Faculty of Science and Technology, Thammasat University, and Roi-Et Agricultural Research and Development Center for providing research facilities. The authors are grateful to Miss Arunthip Hemathulin for her assistance in the paddy field management and data collection.

\section{Supplementary Materials}

Figure 1S. Total rainfall, relative humidity, temperature, and solar radiation after the anhesis stage at eight environments: Pathum Thani location in the growing season 2017 (a), Sakon Nakhon location in the growing season 2017 (b), Ubon Ratchathani location in the growing season 2017 (c), Roi-Et location in the growing season 2017 (d), Pathum Thani location in the growing season 2018 (e), Sakon Nakhon location in the growing season 2018 (f), Ubon Ratchathani location in the growing season 2018 (g), and Roi-Et location in the growing season 2018 (h). (Supplementary Materials)

\section{References}

[1] P. Sharifi, H. Aminpanah, R. Erfani, A. Mohaddesi, and A. Abbasian, "Evaluation of genotype $\times$ environment interaction in rice based on AMMI model in Iran," Rice Science, vol. 24, no. 3, pp. 173-180, 2017.

[2] P. Goufo and H. Trindade, "Rice antioxidants: phenolic acids, flavonoids, anthocyanins, proanthocyanidins, tocopherols, tocotrienols, $\gamma$-oryzanol, and phytic acid," Food Science \& Nutrition, vol. 2, no. 2, pp. 75-104, 2014.

[3] M. Zubair, F. Anwar, M. Ashraf, and M. K. Uddin, "Characterization of high-value bioactives in some selected varieties of Pakistani rice (Oryza sativa L.)," International Journal of Molecular Sciences, vol. 13, no. 4, pp. 4608-4622, 2012.

[4] P. Pokkanta, P. Sookwong, M. Tanang, S. Setchaiyan, P. Boontakham, and S. Mahatheeranont, "Simultaneous determination of tocols, $\gamma$-oryzanols, phytosterols, squalene, cholecalciferol and phylloquinone in rice bran and vegetable oil samples," Food Chemistry, vol. 271, pp. 630-638, 2019.
[5] S. Fasahat, A. Abdullah, K. Muhammad, and R. Wickneswari, "Expression of a key gene involved in the biosynthetic pathway of vitamin E in red pericarp and white rice grains," International Food Research Journal, vol. 20, no. 6, pp. 3395-3401, 2013.

[6] J. C. Taylor, L. Rapport, and G. B. Lockwood, "Octacosanol in human health,” Nutrition, vol. 19, no. 2, pp. 192-195, 2003.

[7] F. Marangoni and A. Poli, "Phytosterols and cardiovascular health," Pharmacological Research, vol. 61, no. 3, pp. 193-199, 2010.

[8] M. N. N. Prasad, K. R. Sanjay, M. S. Khatokar, M. N. Vismaya, and S. N. Swamy, "Health benefits of rice bran-a review," Journal of Nutrition \& Food Sciences, vol. 1, no. 3, pp. 1-7, 2011.

[9] T. S. Rathna-Priya, A. R. L. Eliazer-Nelson, K. Ravichandran, and U. Antony, "Nutritional and functional properties of coloured rice varieties of South India: a review," Journal of Ethnic Foods, vol. 6, no. 11, pp. 1-6, 2019.

[10] R. Sompong, S. Siebenhandl-Ehn, G. Linsberger-Martin, and E. Berghofer, "Physicochemical and antioxidative properties of red and black rice varieties from Thailand, China and Sri Lanka," Food Chemistry, vol. 124, no. 1, pp. 132-140, 2011.

[11] E. G. N. Mbanjo, T. Kretzschmar, H. Jones et al., "The genetic basis and nutritional benefits of pigmented rice grain," Frontiers in Genetics, vol. 11, p. 229, 2020.

[12] K. Pitija, M. Nakornriab, T. Sriseadka, A. Vanavichit, and S. Wongpornchai, "Anthocyanin content and antioxidant capacity in bran extracts of some Thai black rice varieties," International Journal of Food Science \& Technology, vol. 48, no. 2, pp. 300-308, 2013.

[13] S. Sing, H. Lee, S. Wong, C. Bong, and P. Yiu, "Ferulic acid, gamma oryzanol and GABA content in whole grain rice and their variation with bran colour," Emirates Journal of Food and Agriculture, vol. 27, no. 9, pp. 706-711, 2015.

[14] J. Bocianowski, J. Ksiezak, and K. Nowosad, "Genotype by environment interaction for seeds yield in pea (Pisum sativum L.) using additive main effects and multiplicative interaction model," Euphytica, vol. 215, no. 191, pp. 1-10, 2019.

[15] X.-Q. Wang, K.-W. Kim, S.-H. Chu et al., "Genome-wide association study for squalene contents and functional haplotype analysis in rice," ACS Omega, vol. 4, no. 21, pp. 19358-19365, 2019.

[16] C. J. Berman and Z. Xu, “"Genotype and environment effects on tocopherol, tocotrienol, and $\gamma$-oryzanol contents of Southern U.S. rice," Cereal Chemistry, vol. 80, no. 4, pp. 446-449, 2003.

[17] F. D. Goffman, S. Pinson, and C. Bergman, "Genetic diversity for lipid content and fatty acid profile in rice bran," Journal of the American Oil Chemists' Society, vol. 80, no. 5, pp. 485-490, 2003.

[18] A. Miller and K.-H. Engel, "Content of $\gamma$-oryzanol and composition of steryl ferulates in Brown rice (oryza sativa L.) of European origin," Journal of Agricultural and Food Chemistry, vol. 54, no. 21, pp. 8127-8133, 2006.

[19] T. Nurmi, A. M. Lampi, L. Nystro, and V. Piironen, "Effects of environment and genotype on phytosterols in wheat in the HEALTHGRAIN diversity screen," Journal of Agricultural and Food Chemistry, vol. 58, no. 17, pp. 9814-9823, 2010.

[20] S. A. Eberhart and W. A. Russell, "Stability parameters for comparing varieties 1," Crop Science, vol. 6, no. 1, pp. 36-40, 1966.

[21] B. T. Jain, A. K. Sarial, R. P. Saharan, H. Harikesh, and H. Anuragi, "AMMI biplot analysis for stability in basmati rice (Oryza sativa L.) in different production systems," 
Electronic Journal of Plant Breeding, vol. 9, no. 2, pp. 502-510, 2018.

[22] W. Jaruchai, T. Monkham, S. Chankaew, B. Suriharn, and J. Sanitchon, "Evaluation of stability and yield potential of upland rice genotypes in North and Northeast Thailand," Journal of Integrative Agriculture, vol. 17, no. 1, pp. 28-36, 2018.

[23] S. L. Krishnamurthy, P. C. Sharma, D. K. K. Sharma et al., "Identification of mega-environments and rice genotypes for general and specific adaptation to saline and alkaline stresses in India," Scientific Reports, vol. 7, no. 7968, pp. 1-14, 2018.

[24] F. L. Silva, P. C. Soares, A. Cargnin et al., "Methods of adaptability and stability analysis in irrigated rice genotypes in Minas Gerais, Brazil," Cropp Breeding and Applied Biotechnology, vol. 8, no. 2, pp. 119-126, 2008.

[25] B. K. Senapati, A. K. Senapati, and D. Maiti, "Adaptability of some photo insensitive rice genotypes at coastal saline zone of West Bengal," Indian Council of Agricultural Research, vol. 6, no. 1, pp. 17-20, 2009.

[26] R. Aslim R, G. M. E. Manurung, and D. A. Van Sanford, "Genotype $\mathrm{x}$ environment interaction and stability of yield components among rice genotypes in Riau province, Indonesia," SABRAO Journal of Breeding \& Genetics, vol. 44, no. 1, pp. 102-111, 2012.

[27] B. Harakotr, K. Prompoh, S. Boonyuen, B. Suriharn, and K. Lertrat, "Variability in nutraceutical lipid content of selected rice (Oryza sativa L. ssp. indica) germplasms," Agronomy, vol. 9, no. 12, pp. 1-13, 2019.

[28] National Bureau of Agricultural Commodity and Food Standards, "Ministry of agriculture and cooperatives," Good Agricultural Practices for Rice, National Bureau of Agricultural Commodity and Food Standards, Bangkok, Thailand, Thai Agricultural Standard, ID TAS 4401-2008, 2008.

[29] S. Butsat and S. Siriamornpun, "Antioxidant capacities and phenolic compounds of the husk, bran and endosperm of Thai rice," Food Chemistry, vol. 119, no. 2, pp. 606-613, 2010.

[30] S. Siriamornpun, E. Tangkhawanit, and N. Kaewseejan, "Reducing retrogradation and lipid oxidation of normal and glutinous rice flours by adding mango peel powder," Food Chemistry, vol. 201, pp. 160-167, 2016.

[31] K. A. Gomez and A. A. Gomez, Statistical Procedure for Agricultural Research, John Wiley \& Sons, New York, NY, USA, 1984.

[32] K. Finlay and G. Wilkinson, "The analysis of adaptation in a plant-breeding programme," Australian Journal of Agricultural Research, vol. 14, no. 6, pp. 742-754, 1963.

[33] L. Bazrkar-Khatibani, B.-A. Fakheri, M. Hosseini-Chaleshtori, A. Mahender, N. Mahdinejad, and J. Ali, "Genetic mapping and validation of quantitative trait loci (QTL) for the grain appearance and quality traits in rice (Oryza sativa L.) by using recombinant inbred line (RIL) population," International Journal of Genomics, vol. 2019, pp. 1-13, Article ID 3160275 , 2019.

[34] R. Belleggia, C. Platani, F. Nigro, P. de Vita, L. Cattivelli, and R. Papa, "Effect of genotype, environment and genotype-byenvironment interaction on metabolite profiling in durum wheat (Triticum durum Desf.) grain," Journal of Cereal Science, vol. 57, no. 2, pp. 183-192, 2013.

[35] B. J. Lloyd, T. J. Siebenmorgen, and K. W. Beers, "Effects of commercial processing on antioxidants in rice bran," Cereal Chemistry Journal, vol. 77, no. 5, pp. 551-555, 2000.

[36] A. Kuczyńska, V. Cardenia, P. Ogrodowicz, M. Kempa, M. T. Rodriguez-Estrada, and K. Mikołajczak, "Effects of multiple abiotic stresses on lipids and sterols profile in barley leaves (Hordeum vulgare L.)," Plant Physiology and Biochemistry: PPB, vol. 141, pp. 215-224, 2019.

[37] L. Aguirreza'bal, Y. Lavaud, G. Dosio, N. Izquierdo, F. H. Anderade, and L. M. Gonzalez, "Intercepted solar radiation during seed filling determines sunflower weight per seed and oil concentration," Crop Science, vol. 43, no. 1, pp. 152-161, 2003.

[38] R. E. Boyles, Z. W. Brenton, and S. Kresovich, "Genetic and genomic resources of sorghum to connect genotype with phenotype in contrasting environments," The Plant Journal, vol. 97, no. 1, pp. 19-39, 2018.

[39] V. Marwede, A. Schierholt, C. Möllers, and H. C. Becker, "Genotype $\times$ environment interactions and heritability of tocopherol contents in canola," Crop Science, vol. 44, no. 3, pp. 728-731, 2004.

[40] D. Wang, Y. Wang, W. Long et al., "SGD1, a key enzyme in tocopherol biosynthesis, is essential for plant development and cold tolerance in rice," Plant Science, vol. 260, pp. 90-100, 2017.

[41] Y.-H. Niu and L. T. Ng, "Effects of soil salinity on tocopherols, tocotrienols, and $\gamma$-oryzanol accumulation and their relation to oxidative stress in rice plants," Crop Science, vol. 56, no. 6, pp. 3143-3151, 2016.

[42] Y. Qi, D. Zhang, H. Zhang et al., "Genetic diversity of rice cultivars (Oryza sativa L.) in China and the temporal trends in recent fifty years," Chinese Science Bulletin, vol. 51, no. 6, pp. 681-688, 2006. 